\title{
Influence of Local Wind Conditions on the Flight Speed of the Great Cormorant Phalacrocorax carbo
}

\author{
Ken Yoda, ${ }^{1}$ Tadashi Tajima, ${ }^{1}$ Sachiho Sasaki, ${ }^{1}$ Katsufumi Sato, ${ }^{2}$ and Yasuaki Niizuma ${ }^{3}$ \\ ${ }^{1}$ Graduate School of Environmental Studies, Nagoya University, Furo-cho, Chikusa-ku, Nagoya 464-8601, Japan \\ ${ }^{2}$ International Coastal Research Center, Atmosphere and Ocean Research Institute, University of Tokyo, \\ 5-1-5 Kashiwanoha, Kashiwa, Chiba 277-8564, Japan \\ ${ }^{3}$ Faculty of Agriculture, Meijo University, 1-501 Shiogamaguchi, Tenpaku-ku, Nagoya 468-9502, Japan
}

Correspondence should be addressed to Ken Yoda, yoda.ken@nagoya-u.jp

Received 13 June 2012; Revised 3 August 2012; Accepted 14 November 2012

Academic Editor: Inma Estevez

Copyright (C) 2012 Ken Yoda et al. This is an open access article distributed under the Creative Commons Attribution License, which permits unrestricted use, distribution, and reproduction in any medium, provided the original work is properly cited.

In seabirds, the relationship between flight speed and wind direction/speed is thought to be particularly important for studying energy-saving strategy and foraging habitat selection. In this study, we examined whether the ground and calculated air speeds of four great cormorants (Phalacrocorax carbo) were affected by wind conditions using high-resolution GPS data loggers. The birds increased their ground flight speed in tailwinds, decreased it in headwinds, and changed their air speed in relation to wind components. However, they did not change their foraging sites according to the wind conditions. They were likely to respond to moderate wind conditions by adjusting their air speed without changing their foraging sites.

\section{Introduction}

Understanding how environmental factors affect animal movements is of central importance to movement ecology [1]. In seabirds, the relationship between flight speed and wind direction/speed is thought to be particularly important for studying energy-saving strategy and foraging habitat selection and has been well examined $[2,3]$. For example, the family Procellariiformes is likely to favour side or tailwinds at large scales (thousands of kilometres) $[4,5]$, which can reduce their energy expenditure [4] or lead sexually dimorphic species to be segregated in foraging areas [6]. Thus, the effects of winds are expected to exert strong selection pressures on morphology, behaviour, and the life histories of birds $[7,8]$. However, several factors can bias the relationship between wind and flight speed in seabirds, especially at fine spatial scales (several to tens of kilometres). First, the flight paths of seabirds are often convoluted, making it difficult to relate flight paths with wind conditions. Second, because wind conditions change dramatically during short time periods, large-scale meteorology such as satellite-derived wind data is insufficient for detecting the effects of winds on bird flight at fine scales. Third, conventional analyses of air speed have been used in many bird studies (see papers cited in [9]), but this leads to erroneous interpretations of wind effects on bird flight [10]; statistically rigorous approaches need to be used [9].

In this study, we deployed fine-scaled GPS data loggers on free-ranging great cormorants (Phalacrocorax carbo) to evaluate the effects of winds on their ground speed (i.e., the speed of the bird with respect to the ground) and calculated air speed (i.e., the speed relative to the air in which the bird is flying). Cormorants often commute in a straight line to memorised foraging areas [11-13] and use powered flight with uninterrupted flapping without gliding; therefore, they are suitable for examining wind effects on seabird movements and expected to follow the theory of powered flight (e.g., [14]). In addition, because the maximum foraging range of the great cormorant is relatively small (less than $15 \mathrm{~km}$; [15]), we could use local wind measurements that would be nearly identical to the winds that the birds encountered. We examined whether the ground and calculated air speeds of great cormorants were affected by wind conditions and we determined if they changed foraging sites according to wind conditions. 


\section{Materials and Methods}

This study was conducted in June 2010 at the Unoyama breeding colony $\left(34^{\circ} 48^{\prime} \mathrm{N}, 136^{\circ} 53^{\prime} \mathrm{E}\right)$ and the Ishigakiike colony $\left(34^{\circ} 51^{\prime} \mathrm{N}, 136^{\circ} 36^{\prime} \mathrm{E}\right)$ in the Tokai region of Japan. Great cormorants nest on trees in these regions [16]. Because they temporally leave their nests when humans approach, we used alpha-chloralose (Tokyo Chemical Industry Co., Ltd., Tokyo, Japan) to capture specimens. Alpha-chloralose is an anaesthetic and it allowed us to capture cormorants safely. We inserted 35-40 mg of alpha-chloralose powder into the mouth of a fish (e.g., ayu Plecoglossus altivelis) and placed it on a nest that contained chicks using a fishing rod. After a bird ate the fish and was immobilised (within 1-2 h), we captured it. In total, we captured eight birds in this way. No birds were injured during the procedure. The procedures used in this study were approved by the Ministry of the Environment, Japan.

We deployed GPS loggers on four breeding adults, we deployed acceleration data loggers on two other birds for different research purposes, and we did not deploy any loggers on the remaining two birds. A small plastic base was attached to the bird's back feathers with adhesive tape (Tesa, Hamburg, Germany) and glue (Loctite 401). A data logger was attached using a cable tie that could be cut remotely (RC-150-150T, Little Leonard, Tokyo, Japan), which entered beneath the feathers that were glued to the base. To avoid having to recapture of birds using alpha-chloralose, we used a remote release system that could send a signal to cut the cable tie (RX-100N, Little Leonard). After several days of attachment, we recovered the data loggers when the birds were on their nests.

A GPS data logger consisted of a GPS receiver with an antenna (GiPSy, Technosmart, Rome, Italy) and it was powered by a $\mathrm{Li}_{-} \mathrm{SOCl}_{2}$ battery (LS14500, SAFT, Paris, France). The GPS loggers were programmed to take positional fixes every 9 or $20 \mathrm{~s}$. The overall mass was 59-84 g, which corresponded to $<5 \%$ of each bird's body mass. The birds did not appear to be negatively affected by the loggers or from being handled by the researchers.

We calculated trip duration and trip range, which was defined as the maximum distance from the colony. The cormorants commuted in a straight line without stopovers (Figure 1); therefore, we could easily define outward and homing flights using the sudden initial decrease and the final increase in ground flight speed, which marked the first flight and the final flight, respectively, during the trip (Figure 2). We defined foraging time as the period between the outward and homing flights; the foraging area was identified as the area where the bird remained during that period. For each outward and homing flight, flight speed and direction were averaged.

Wind direction and speed were recorded at two climatological stations operated by the Japan Meteorological Agency (JMA). We used 10-min wind direction and speed measurements for each outward and homing flight. For each flight, several wind measurements were averaged. The weather stations were within $15 \mathrm{~km}$ of each colony (Figure 1; Minamichita station: $34^{\circ} 44^{\prime} \mathrm{N}, 136^{\circ} 56^{\prime} \mathrm{E}, 6.5 \mathrm{~m}$ asl; Tsu station: $34^{\circ} 44^{\prime} \mathrm{N}, 136^{\circ} 31^{\prime} \mathrm{E}, 39.6 \mathrm{~m}$ asl). For the outward and homing flights of each foraging trip, the absolute difference in the angle between flight direction and wind direction (i.e., $0-180^{\circ}$ ) was calculated. Wind speed in the direction of flight was calculated as the product of wind speed and the cosine of the angle. We calculated air speed using ground speed, wind speed, and the angle between the ground and wind vectors.

To examine the relationship between ground flight speed and wind speed in the direction of flight, a linear mixed model that treated individual birds as a random effect was run using the lme4 package in the statistical software R [17]. The significance of the fixed effects, as well as their 95\% confidence intervals, was obtained from 100,000 Markov chain Monte Carlo (MCMC) simulations performed using the pvals.fnc function in $\mathrm{R}$ [18].

A two-dimensional generalised additive model (GAM) was used to analyse the relationship between air speed and wind [9]. The GAM was used instead of the conventional method that tests the relationship between air speed as a function of ground speed and air speed (see papers cited in [9]) because the conventional analysis can produce erroneous correlations $[9,10]$. We divided the wind variable into two components (i.e., zonal and meridional components); the eastern direction was represented by positive values of $x_{w}$ and the northern direction by positive values of $y_{w}$. The two variables were implemented in a GAM by first transforming them via a LOESS smoother (a locally weighted regression) with a maximum span of $80 \%$ and 2 degrees of freedom, following [9]. To fit the GAM, we used the gam package in $\mathrm{R}$ [19].

To examine the degree of overlap in foraging areas between successive trips, we calculated the proportion of the foraging area of one trip that was covered by the foraging area of another trip, that is $\operatorname{HR}[i, j]=\mathrm{A}[i, j] / \mathrm{A}[i]$, where $\mathrm{A}[i, j]$ is the area of the intersection between the two foraging areas and $\mathrm{A}[i]$ is the foraging area of trip $i[20]$. These were calculated for two birds that conducted six successive trips. This analysis was performed using the adehabitat package in $\mathrm{R}$ [21]. We excluded one trip from this analysis because the bird's position was not obtained consistently in the foraging area (Trip no. 4 in Table 1).

Data were analysed using Matlab version 7.1 (MathWorks, Inc., Natick, MA, USA) and R version 2.14.1 [22].

\section{Results}

We obtained GPS data from four birds with body masses ranging from 1570 to $2140 \mathrm{~g}$ (mean $=1905 \mathrm{~g}$ ). The birds were named A, B (Unoyama colony), C, and D (Ishigakiike colony). The GPS loggers recorded 15 trips that consisted of 12 complete trips and 3 trips with truncated data due to exhausted batteries. Mean trip duration and trip range were $5.1 \pm 4.8 \mathrm{~h}(0.7-19.0 \mathrm{~h}, n=12)$ and $13.1 \pm 3.8 \mathrm{~km}$ $(8.6-18.7 \mathrm{~km}, n=12)$, respectively, for complete trips. For the truncated data, we only used the outward flights in our analysis. Finally, we obtained 27 outward and homing paths.

Average flight duration was $11 \mathrm{~min}(4-23 \mathrm{~min}, n=27)$. Average wind speed on each path was $2.7 \pm 1.4 \mathrm{~m} / \mathrm{s}(0.8-5.3$, 


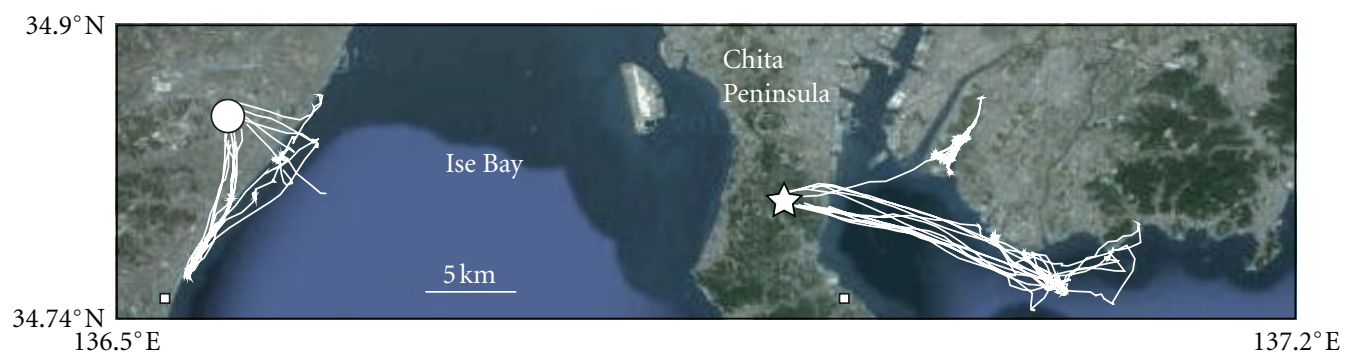

FIGURE 1: GPS tracks for four great cormorants during 15 foraging trips. The star and circle indicate the Unoyama and Ishigakiike breeding colonies, respectively. The two squares indicate the closest meteorological stations to each colony from which we derived wind information.
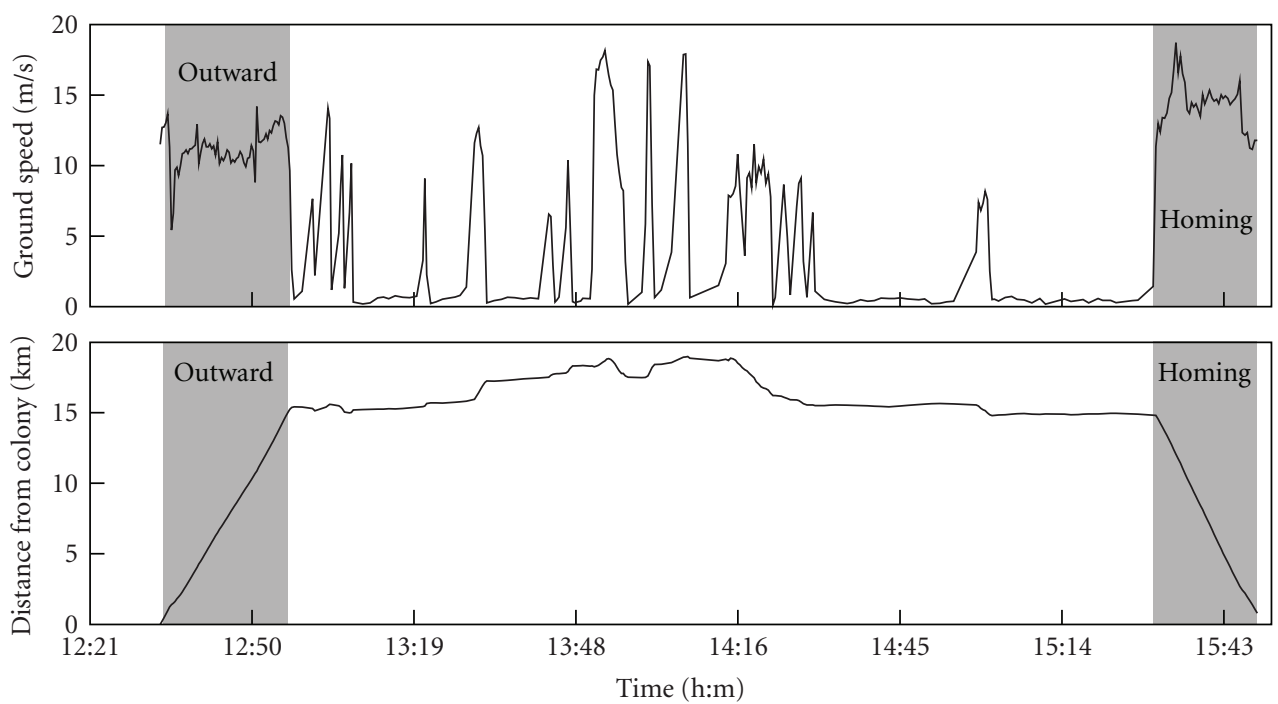

Figure 2: Example of time-series data of ground flight speed and distance from the colony. The shadows indicate outward and homing flights.

$n=27)$. Mean ground and air speeds on the paths were $14.4 \pm 1.7 \mathrm{~m} / \mathrm{s}(11.2-18.5, n=27)$ and $14.6 \pm 1.3 \mathrm{~m} / \mathrm{s}(11.2-$ $17.5, n=27$; Figure $4(\mathrm{a}))$, respectively.

Ground flight speed increased significantly with wind strength relative to the birds (Figure 4(b)). A linear mixed model estimated $S=0.70( \pm 0.10,0.48-0.91$; SD, 95\% CI $)$. $W+14.4( \pm 0.31,13.4-15.1)$, where $S$ and $W$ were ground flight speed and wind speed, respectively, in the direction of flight $(P<0.001)$. Air speed was significantly related to $x_{w}$ $(F=5.2, P<0.05)$, but not to $y_{w}(F=1.7, P=0.2)$. Thus, air speed was only influenced by wind that was blowing eastwest (Figure 5).

Successive trips by two birds qualitatively showed high foraging-site fidelity and the foraging areas overlapped (Table 1; Figure 6).

\section{Discussion}

Great cormorants encountered various wind speeds and directions (Figure 3). The birds sometimes encountered contrasting wind conditions between outward and homing trips. Although sample size was small (four individuals), our data clearly demonstrated that the ground speed of great cormorants can be predicted by wind speed in the direction of flight (Figure 4(b)). Their ground flight speed increased in tailwinds and decreased in headwinds. Qualitatively, this matches very well with observations from visual surveys in which ground flight speeds of great cormorants in tailwinds were higher than in headwinds [23]. In addition, [23] reported a mean ground speed of $18.8 \mathrm{~m} / \mathrm{s}$ in a strong tailwind $(6.5 \mathrm{~m} / \mathrm{s})$, which agrees very well with our mixedmodel prediction of $19.0 \mathrm{~m} / \mathrm{s}$. On the other hand, [23] also reported a ground speed of $12.4 \mathrm{~m} / \mathrm{s}$ in an extreme headwind $(8.0 \mathrm{~m} / \mathrm{s})$, which was higher than our predicted value of $8.8 \mathrm{~m} / \mathrm{s}$ in a similar wind. Great cormorants prefer to fly close to the ground (i.e., ground effect; weak wind speeds closer to the ground $\sim 0.3 \mathrm{~m}$ ) when flying into strong headwinds [23]; therefore, our predictive equation seems to underestimate their ground speed in such extreme headwinds, that is, outside our measured range ( $>5 \mathrm{~m} / \mathrm{s}$ of wind speed).

The calculated air speeds of our birds $(14.6 \mathrm{~m} / \mathrm{s})$ ranged between previously reported minimum power speeds $\left(V_{\mathrm{mp}}\right)$ for this species (13.5 [24] to $16.5 \mathrm{~m} / \mathrm{s}$ [23]), which is the speed at which the least mechanical power is required from the flight muscles to maintain the bird flying at a constant air speed [25]. Therefore, great cormorants might adopt $V_{\mathrm{mp}}$ as 


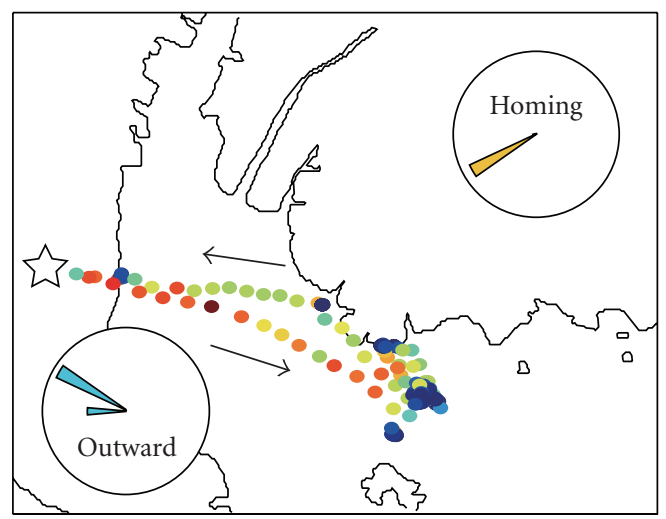

Wind speed (m/s)
$\begin{array}{lll}\square-4 & \square & 1-2 \\ \square & 2-3 & 0\end{array}$

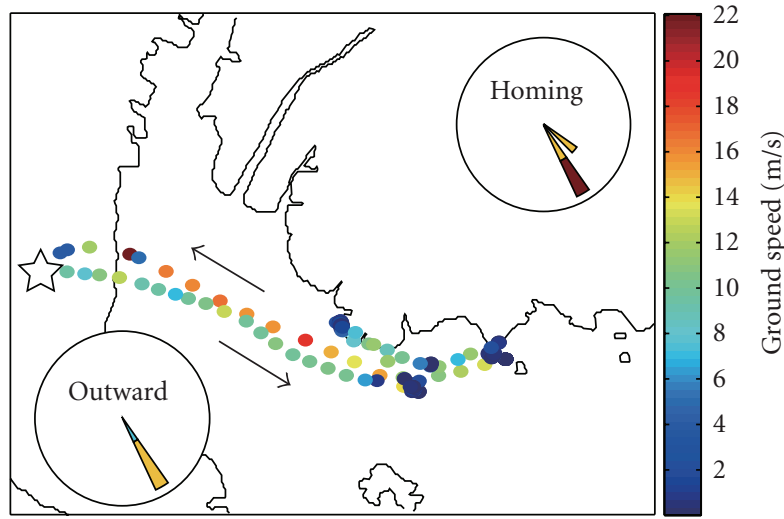

Wind speed $(\mathrm{m} / \mathrm{s})$
$\square$ 3-4
$\square \quad 1-2$
$\square 2-3 \square 0-1$

(a)

(b)

FIgure 3: Two examples of wind conditions and GPS positions. The Bird A encountered different wind conditions between outward and homing trips in (a) Trip no. 2 and (b) Trip no. 6, respectively. The star indicates the Unoyama breeding colony. The dots show the GPS positions that were interpolated at $1 \mathrm{~min}$ to produce a clearer display and the colour indicates the ground speed of the bird. Arrows indicate travel direction. The two rose plots on each panel show the frequency of occurrence of wind direction, which is the direction from which the wind was blowing (not where it was blowing to), and wind speed (colour) during outward and homing flights.

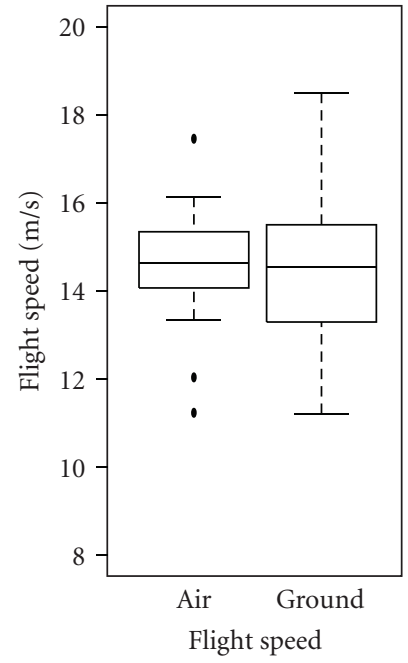

(a)

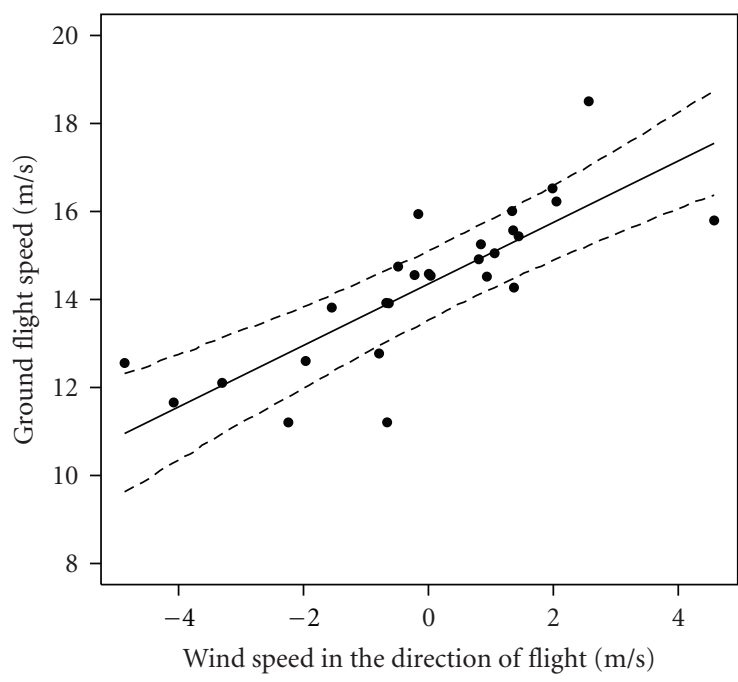

(b)

FIGURE 4: (a) Measured ground speeds and calculated air speeds for great cormorants and (b) the relationship between ground speed and wind speed in the direction of flight (tailwind component along the track direction). The solid line is the best fit that was estimated by a linear mixed model: the dashed lines indicate the $95 \%$ confidence intervals.

was indicated for Kerguelen shag P. verrucosus [26]. However, the great cormorants showed changes in calculated air speed in relation to wind components (Figure 5). Optimal flight theory predicts that $V_{\mathrm{mp}}$ will be unaffected by winds [7]; therefore, air speed optimization [27] might explain changes in calculated air speed in relation to wind conditions, as found in this study. Because air and ground flight speed are approximately equivalent in calm wind conditions, the actual air speed in this study might show the same relationship to the wind as the ground speed (Figure 4(b)). If air speed decreases in tailwinds and increases in headwinds, this means that the birds adopted maximum range speed $\left(V_{\mathrm{mr}}\right)$, which is the air speed where energy expenditure per distance travelled is minimal [27], and our data might support the optimality theory in relation to wind condition. Further study that incorporates morphological and actual air-speed measurements would be needed to clarify this issue.

Notably, the great cormorants showed strong foragingsite fidelity (Table 1; Figure 6), which is common in cormorants $[12,28,29]$, irrespective of wind conditions. This 


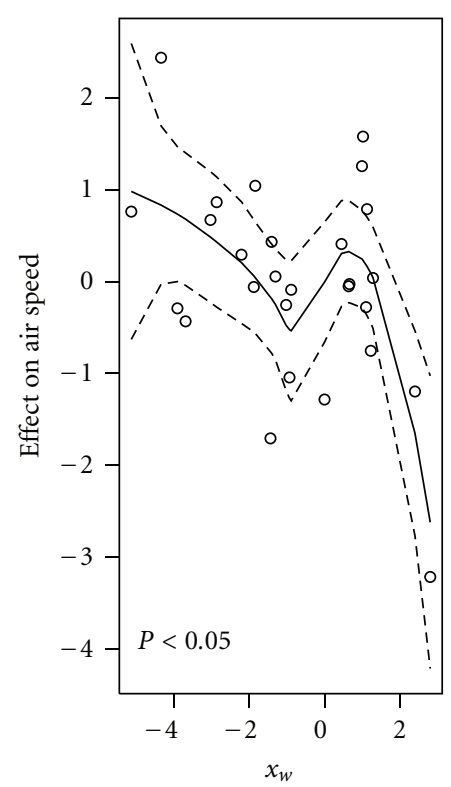

(a)

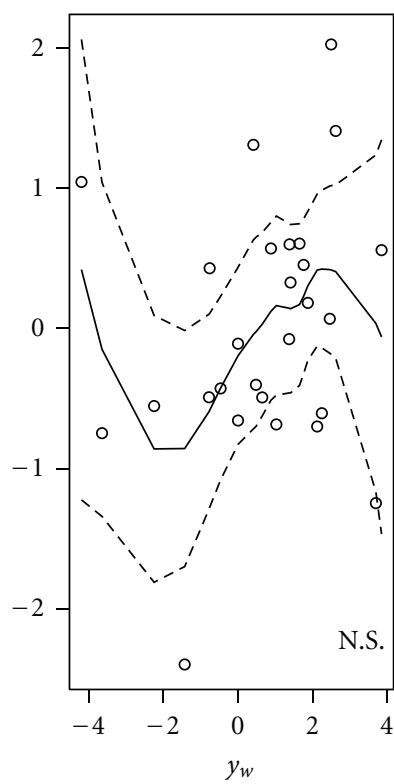

(b)

FIGURE 5: The predicted relative influence of the wind components $\left(x_{w}\right.$ and $\left.y_{w}\right)$ on the air speed of great cormorants. The eastern direction was represented by positive values of $x_{w}$ and the northern direction by positive values of $y_{w}$. Calculated air speed was significantly related to $x_{w}$, but not to $y_{w}$. The solid lines are the fitted functional response and the broken lines represent standard error curves.

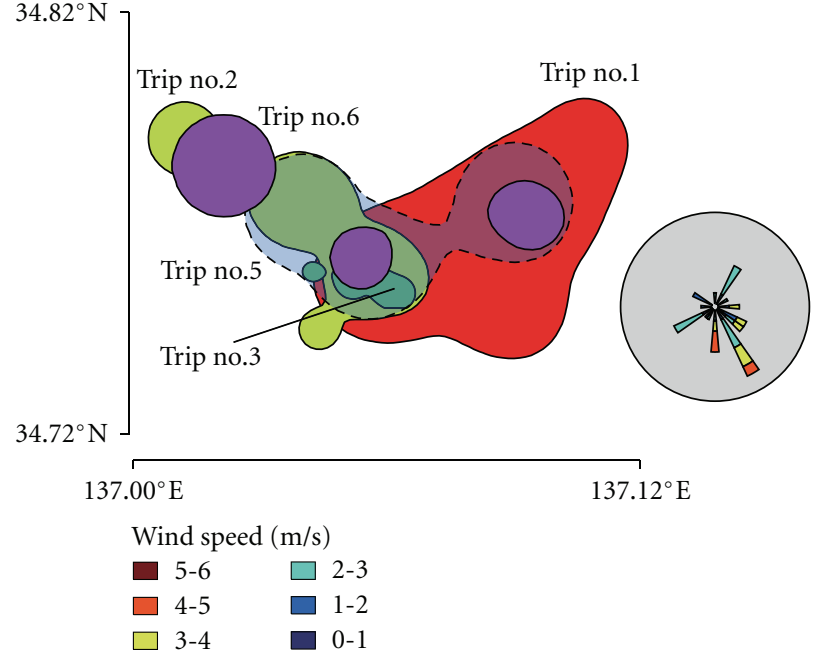

(a)

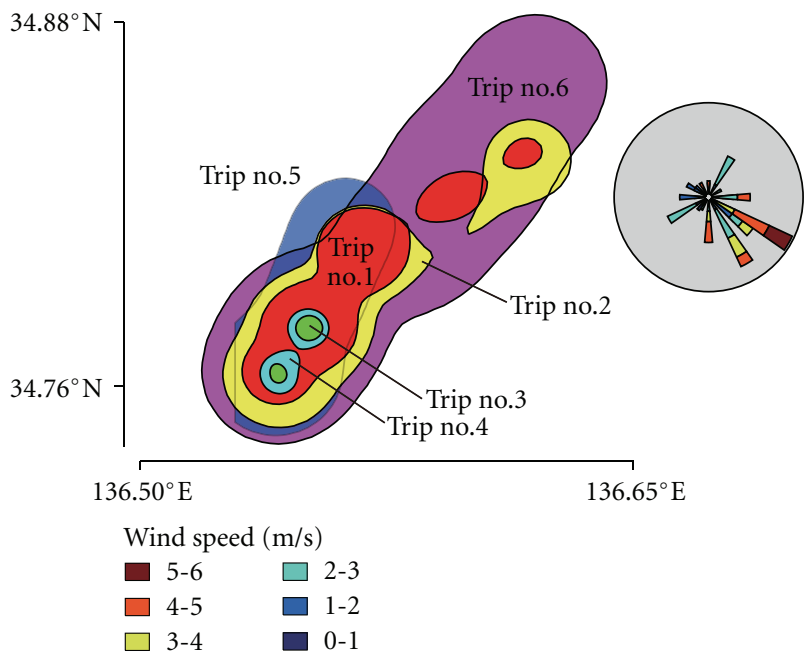

(b)

Figure 6: Foraging area overlap in two great cormorants that conducted multiple foraging trips. The 95\% contours of the kernel density estimates of the foraging areas are shown for (a) Bird A and (b) Bird C (see Table 1). The two rose plots show the frequency of occurrence of wind direction, which is the direction from which the wind was blowing (not where it was blowing to), and wind speed (colour) during outward and homing flights.

might be related to low predictability of wind conditions in this study area, and therefore, foraging site selection based on wind would not be efficient in contrast to some seabirds that live in "predictable" local wind conditions at large spatial scales $[3,5,29]$. In addition, because the cormorants using pure powered flight could not efficiently extract energy compared to gliders such as shearwaters [5], albatrosses [4], boobies, and gannets $[3,30]$, they did not select foraging sites based on winds. The significant levels of foraging-site fidelity in successive foraging trips also suggest that their prey may be predictable in space within a period of several days and that the cormorants are able to remember specific foraging sites $[12,31,32]$. In general, seabirds with small foraging ranges and corresponding short trip durations, as was the case in this study ( $5 \mathrm{~h}$ in mean trip duration), are likely to have higher foraging site fidelity because the low probability of 
TABLE 1: Foraging area overlap in two great cormorants, the proportion of the foraging area of one trip that was covered by the foraging area of another trip, that is $\operatorname{HR}[i, j]=\mathrm{A}[i, j] / \mathrm{A}[i]$, where $\mathrm{A}[i, j]$ is the area of the intersection between the two foraging areas and $\mathrm{A}[i]$ is the foraging area of trip $i$. The trip no. 4 of Bird A was not used because the bird's position was not obtained consistently in the foraging area.

\begin{tabular}{|c|c|c|c|c|c|c|}
\hline \multirow{2}{*}{$i$} & \multicolumn{6}{|c|}{$j$} \\
\hline & 1 & 2 & 3 & 4 & 5 & 6 \\
\hline \multicolumn{7}{|c|}{ Bird A } \\
\hline 1 & - & 0.18 & 0.06 & - & 0.46 & 0.14 \\
\hline 2 & 0.39 & - & 0.12 & - & 0.72 & 0.26 \\
\hline 3 & 0.94 & 0.90 & - & - & 0.99 & 0.35 \\
\hline 5 & 0.70 & 0.50 & 0.09 & - & - & 0.24 \\
\hline 6 & 0.47 & 0.39 & 0.07 & - & 0.51 & - \\
\hline \multicolumn{7}{|c|}{ Bird C } \\
\hline 1 & - & 0.87 & 0.04 & 0.13 & 0.72 & 0.99 \\
\hline 2 & 0.54 & - & 0.02 & 0.08 & 0.62 & 0.98 \\
\hline 3 & 1.00 & 1.00 & - & 1.00 & 1.00 & 1.00 \\
\hline 4 & 1.00 & 1.00 & 0.29 & - & 1.00 & 1.00 \\
\hline 5 & 0.59 & 0.82 & 0.03 & 0.11 & - & 0.89 \\
\hline 6 & 0.27 & 0.43 & 0.01 & 0.04 & 0.30 & - \\
\hline
\end{tabular}

extreme changes in food availability [32]. Additionally, one of the main prey of the cormorants in this study area is the mullet (Mugil cephalus) [33], an herbivorous bottom feeder. Therefore, although the distribution might be relatively stable, it could slowly change over time, reflecting subtle movements of foraging sites of the cormorants between their trips (Figure 6).

In conclusion, the ground and air speeds of great cormorants were affected by prevailing wind conditions. However, wind conditions did not produce variations in foraging sites. Thus, great cormorants were likely to respond to moderate wind conditions by adjusting their air speed but without changing the location of foraging sites.

\section{Acknowledgments}

The authors thank H. Fujii, H. Kuroki, and Y. Inoue for their help during data collection. This work was financially supported by Grants from the Japan Society for the Promotion of Science to K. Yoda (20519002 and 24681006) and by the program Bio-Logging Science of the University of Tokyo.

\section{References}

[1] R. Nathan, W. M. Getz, E. Revilla et al., "A movement ecology paradigm for unifying organismal movement research," Proceedings of the National Academy of Sciences of the United States of America, vol. 105, no. 49, pp. 19052-19059, 2008.

[2] M. Mateos-Rodríguez and B. Bruderer, "Flight speeds of migrating seabirds in the Strait of Gibraltar and their relation to wind," Journal of Ornithology, vol. 153, no. 3, pp. 881-889, 2012.

[3] H. Weimerskirch, M. Le Corre, Y. Ropert-Coudert, A. Kato, and F. Marsac, "The three-dimensional flight of red-footed boobies: adaptations to foraging in a tropical environment?" Proceedings of the Royal Society B, vol. 272, no. 1558, pp. 5361, 2005.

[4] H. Weimerskirch, T. Guionnet, J. Martin, S. A. Shaffer, and D. P. Costa, "Fast and fuel efficient? Optimal use of wind by flying albatrosses," Proceedings of the Royal Society B, vol. 267, no. 1455, pp. 1869-1874, 2000.

[5] V. H. Paiva, T. Guilford, J. Meade, P. Geraldes, J. A. Ramos, and S. Garthe, "Flight dynamics of Cory's shearwater foraging in a coastal environment," Zoology, vol. 113, no. 1, pp. 47-56, 2010.

[6] E. D. Wakefield, R. A. Phillips, M. Jason et al., "Wind field and sex constrain the flight speeds of central-place foraging albatrosses," Ecological Monographs, vol. 79, no. 4, pp. 663679, 2009.

[7] A. Hedenström, T. Alerstam, M. Green, and G. A. Gudmundsson, "Adaptive variation of airspeed in relation to wind, altitude and climb rate by migrating birds in the Arctic," Behavioral Ecology and Sociobiology, vol. 52, no. 4, pp. 308$317,2002$.

[8] H. Weimerskirch, M. Louzao, S. de Grissac, and K. Delord, "Changes in wind pattern alter albatross distribution and lifehistory traits," Science, vol. 335, no. 6065, pp. 211-214, 2012.

[9] J. Shamoun-Baranes, E. Van Loon, F. Liechti, and W. Bouten, "Analyzing the effect of wind on flight: pitfalls and solutions," Journal of Experimental Biology, vol. 210, no. 1, pp. 82-90, 2007.

[10] F. Liechti, "Birds: blowin' by the wind?" Journal of Ornithology, vol. 147, no. 2, pp. 202-211, 2006.

[11] F. Quintana, R. Wilson, P. Dell'Arciprete, E. Shepard, and A. G. Laich, "Women from Venus, men from Mars: inter-sex foraging differences in the imperial cormorant Phalacrocorax atriceps a colonial seabird," Oikos, vol. 120, no. 3, pp. 350-358, 2011.

[12] J. Kotzerka, S. A. Hatch, and S. Garthe, "Evidence for foraging -site fidelity and individual foraging behavior of pelagic cormorants rearing chicks in the gulf of Alaska," Condor, vol. 113, no. 1, pp. 80-88, 2011.

[13] H. Weimerskirch, S. Bertrand, J. Silva, J. C. Marques, and E. Goya, "Use of social information in seabirds: compass rafts indicate the heading of food patches," PloS one, vol. 5, no. 3, p. e9928, 2010.

[14] C. J. Pennycuick, Modelling the Flying Bird, Academic Press, London, UK, 2008.

[15] T. Hino and A. Ishida, "Home ranges and seasonal movements of great cormorants Phalacrocorax carbo in the Tokai area, based on GPS-Argos tracking," Japanese Journal of Ornithology, vol. 61, no. 1, pp. 17-28, 2012.

[16] Y. Inoue, K. Yoda, H. Fujii, H. Kuroki, and Y. Niizuma, "Nest intrusion and infanticidal attack on nestlings in great cormorants Phalacrocorax carbo: why do adults attack conspecific chicks?" Journal of Ethology, vol. 28, no. 2, pp. 221-230, 2010.

[17] D. Bates and M. Maechler, "lme4: linear mixed-effects models using S4 classes," R package version 0.999375-42, http://cran.r-project.org/web/packages/lme4/, 2011.

[18] R. H. Baayen, "languageR: data sets and functions with 'Analyzing Linguistic Data: a practical introduction to statistics," R package version 1.4, http://cran.r-project.org/web/ packages/languageR/, 2011.

[19] T. Hastie, "Gam: generalized additive models," R package version 1.06.2, http://cran.r-project.org/web/ packages/gam/, 2012.

[20] J. Fieberg and C. O. Kochanny, "Research and management viewpoint-quantifying home-range overlap: the importance 
of the utilization distribution," Journal of Wildlife Management, vol. 69, no. 4, pp. 1346-1359, 2005.

[21] C. Calenge, "Adehabitat: analysis of habitat selection by animals," R package version 1.8.10, http://cran.r-project.org/ web/packages/adehabitat/, 2012.

[22] R Development Core Team, R: A Language and Environment For Statistical Computing, R Foundation for Statistical Computing, Vienna, Austria, 2011.

[23] J. Finn, J. Carlsson, T. Kelly, and J. Davenport, "Avoidance of headwinds or exploitation of ground effect-why do birds fly low?" Journal of Field Ornithology, vol. 83, no. 2, pp. 192-202, 2012.

[24] B. Bruderer and A. Boldt, "Flight characteristics of birds: I. Radar measurements of speeds," Ibis, vol. 143, no. 2, pp. 178 204, 2001.

[25] C. Pennycuick, P. L. F. Fast, N. Ballerstädt, and N. Rattenborg, "The effect of an external transmitter on the drag coefficient of a bird's body, and hence on migration range, and energy reserves after migration," Journal of Ornithology, vol. 153, no. 3, pp. 633-644, 2012.

[26] Y. Y. Watanabe, A. Takahashi, K. Sato, M. Viviant, and C. A. Bost, "Poor flight performance in deep-diving cormorants," Journal of Experimental Biology, vol. 214, no. 3, pp. 412-421, 2011.

[27] C. J. Pennycuick, "Fifteen testable predictions about bird flight," Oikos, vol. 30, no. 2, pp. 165-176, 1978.

[28] D. Grémillet, R. P. Wilson, S. Storch, and Y. Gary, "Threedimensional space utilization by a marine predator," Marine Ecology Progress Series, vol. 183, pp. 263-273, 1999.

[29] J. T. H. Coleman, M. E. Richmond, L. G. Rudstam, and P. M. Mattison, "Foraging location and site fidelity of the doublecrested Cormorant on Oneida Lake, New York," Waterbirds, vol. 28, no. 4, pp. 498-510, 2005.

[30] S. Garthe, W. A. Montevecchi, and G. K. Davoren, "Flight destinations and foraging behaviour of northern gannets (Sula bassana) preying on a small forage fish in a low-Arctic ecosystem," Deep-Sea Research, vol. 54, no. 3-4, pp. 311-320, 2007.

[31] D. B. Irons, "Foraging area fidelity of individual seabirds in relation to tidal cycles and flock feeding," Ecology, vol. 79, no. 2, pp. 647-655, 1998.

[32] H. Weimerskirch, "Are seabirds foraging for unpredictable resources?” Deep-Sea Research, vol. 54, no. 3-4, pp. 211-223, 2007.

[33] M. Sato, Y. Inoue, M. Ishigaki, R. Yamawaki, Y. Nakagawa, and Y. Niizuma, "Food habit of great cormorants at two locations in Aichi Prefecture," Japanese Journal of Ornithology, vol. 58, no. 2, pp. 196-200, 2009. 

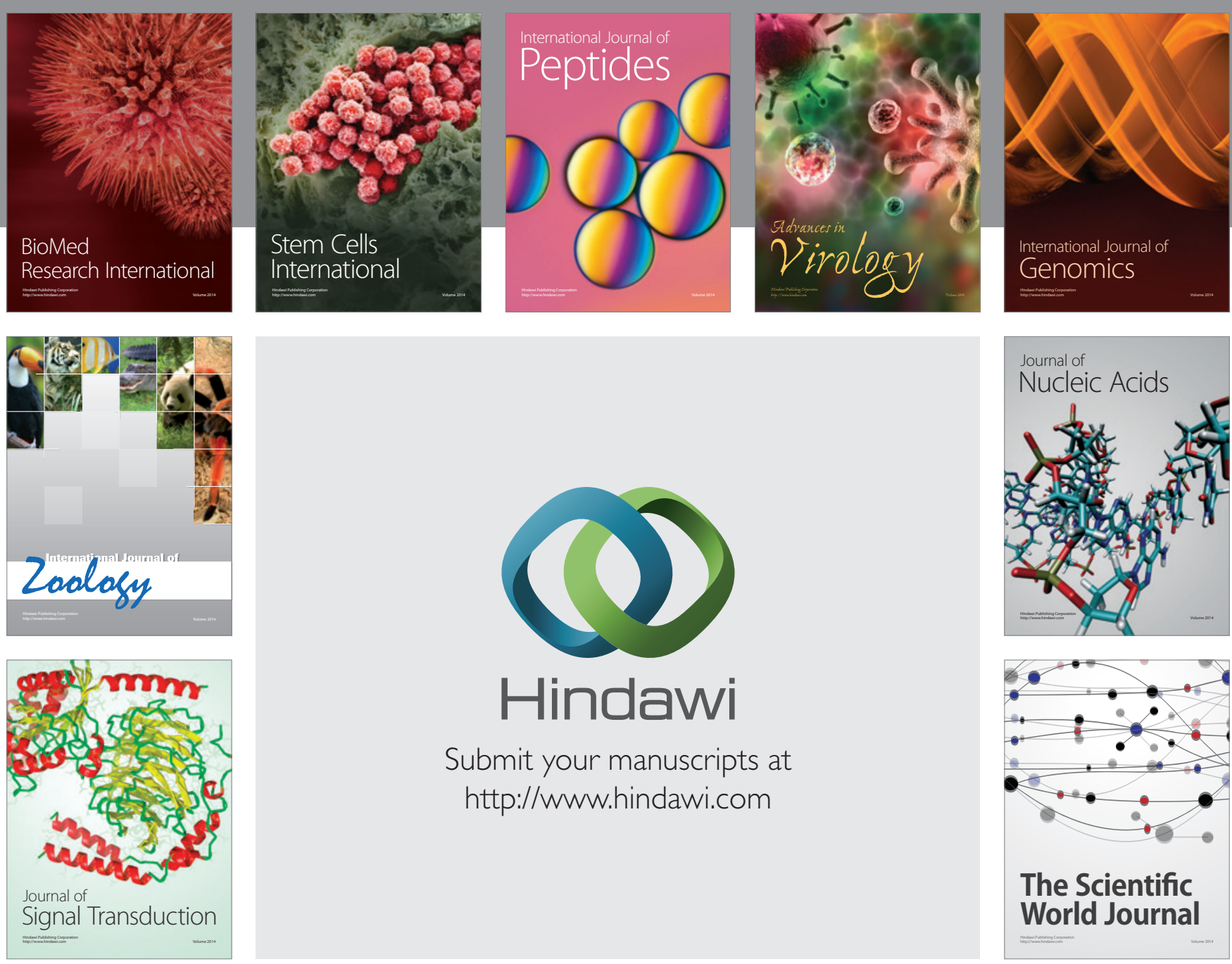

Submit your manuscripts at

http://www.hindawi.com
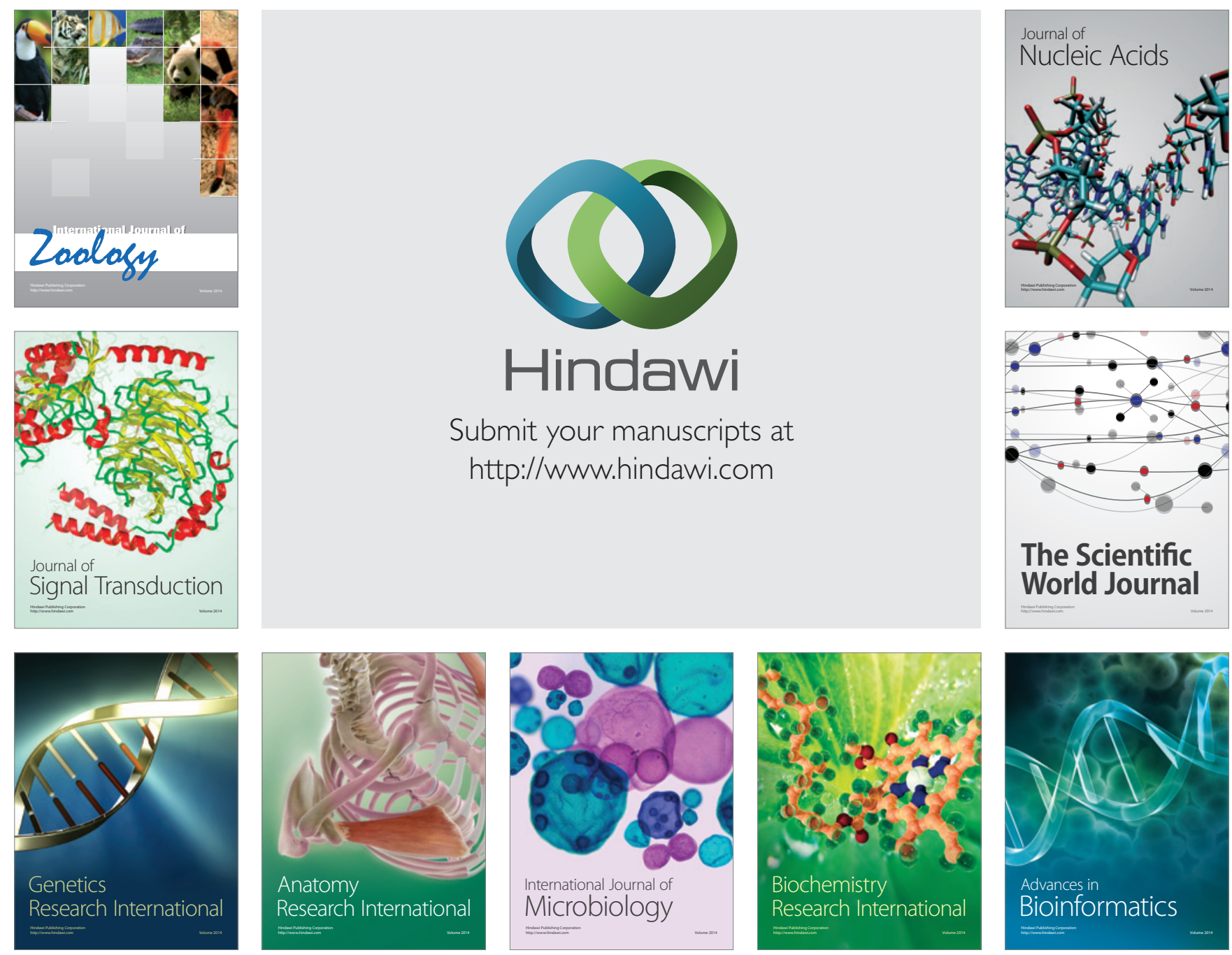

The Scientific World Journal
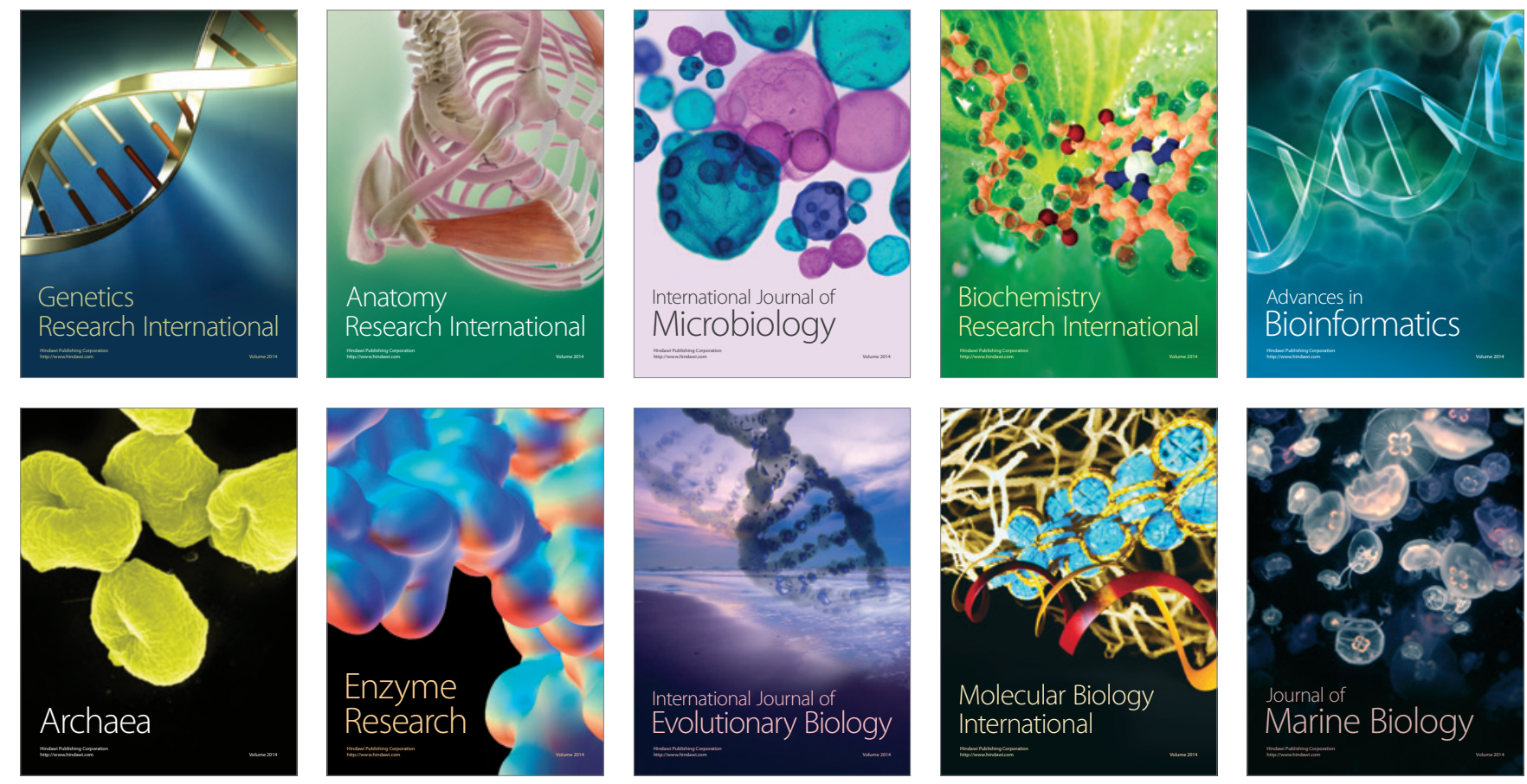